\title{
Correlation of Performance, Exhaust Gas Temperature and Speed of a Spark Ignition Engine Using Kiva4
}

\author{
Joseph Lungu ${ }^{1 *}$, Lennox Siwale ${ }^{1}$, Rudolph Joe Kashinga ${ }^{1}$, Shadreck Chama ${ }^{1}$, Akos Bereczky ${ }^{2}$ \\ ${ }^{1}$ School of Engineering, The Copperbelt University, Riverside Campus, Jambo Drive, Kitwe, Zambia \\ ${ }^{2}$ Department of Energy Engineering, Budapest University of Technology and Economics, Budapest, Hungary \\ Email: *josephlungu8512@gmail.com
}

How to cite this paper: Lungu, J., Siwale, L., Kashinga, R.J., Chama, S. and Bereczky, A. (2021) Correlation of Performance, Exhaust Gas Temperature and Speed of a Spark Ignition Engine Using Kiva4. Journal of Power and Energy Engineering, 9, 53-78. https://doi.org/10.4236/jpee.2021.98004

Received: June 25, 2021

Accepted: August 28, 2021

Published: August 31, 2021

Copyright $\odot 2021$ by author(s) and Scientific Research Publishing Inc. This work is licensed under the Creative Commons Attribution International License (CC BY 4.0).

http://creativecommons.org/licenses/by/4.0/

\begin{abstract}
The objective of this study was to investigate performance characteristics of a spark ignition engine, particularly, the correlation between performance, exhaust gas temperature and speed, using Kiva4. Test data to validate kiva4 simulation results were conducted on a 3-cylinder, four-stroke Volkswagen (VW) Polo 6 TSI 1.2 gasoline engine. Three different tests were, therefore, carried out. In one set, variations in exhaust gas temperature were studied by varying the engine load, while keeping the engine speed constant. In another test, exhaust gas temperature variations were studied by keeping the engine at idling whilst varying the speeds. A third test involved studying variations in exhaust gas temperature under a constant load with variable engine speeds. To study variations in exhaust gas temperatures under test conditions, a basic grid/mesh generator, K3PREP, was employed to write an itape17 file comprising of a $45^{\circ}$ asymmetrical mesh. This was based on the symmetry of the combustion chamber of the engine used in carrying out experimental tests. Simulations were therefore performed based on the input parameters established in the conducted tests. Simulations with the kiva4 code showed a significant predictability of the performance characteristics of the engine. This was evident in the appreciable agreement obtained in the simulation results when compared with the test data, under the considered test conditions. A percentage error, between experimental results and results from simulations with the kiva4 code of only between $2 \%$ to $3 \%$ was observed.
\end{abstract}

\section{Keywords}

Combustion, Kiva4, Gasoline, Exhaust Gas Temperature, Spark Ignition Engine 


\section{Introduction}

Engine performance is critical in understanding the operation of an internal combustion engine. It is usually represented by characteristic curves or characteristic profiles which are a function of engine parameters. Manufacturers of internal combustion engines expect their products to give satisfactory economy, reliability, efficiency and durability under service conditions. Engine ratings indicating the highest power, maximum torque and speed are usually given by manufacturers. Engine performance is defined as how well an engine is operating in relation to the amount of input energy or how effectively it generates useful energy in relation to other engines in comparison [1]. One of the least invasive methods of investigating engine performance involves measurement of exhaust gas temperature (EGT), which can be related to the instant torque through thermodynamic relations. Practical implementation of such a system requires significant consideration of various factors, such as chosen points for temperature detection along the exhaust line, specific for each engine, type of installation for thermocouples, and thermal characteristics of the interposed materials. These factors tend to significantly influence the torque-predictive capabilities [2].

Some of the important parameters are speed, inlet pressure and output temperature, air-fuel ratio etc. The useful range of all these parameters is limited by various factors, like mechanical stresses, knocking and overheating. As such, there is a practical limit of maximum power and engine efficiency. Besides the overall efficiency, various other efficiencies are encountered when dealing with the theory, design and operation of engines. Performance parameters are parameters used to measure performance of an engine; these are power, fuel consumption and efficiency. They are used to evaluate the performance of engines, do a comparative assessment of engines, to determine the general characteristics [3] [4]. Among all these parameters, this article will focus on the exhaust gas temperature (EGT). Indeed, EGT is one of the most meaningful parameters that can be acquired because it is representative of many phenomena occurring in the combustion chambers, and it is responsible for the correct operation of devices located along the exhaust pipeline [3]. Exhaust gas temperature varies through the exhaust process and as the gas flows past the exhaust valves through the exhaust system, temperature tends to decrease. Accurate measurement of exhaust gas temperature (EGT) is required for both on-vehicle applications and in engine research. In vehicles, EGT may be used for catalyst monitoring. In engine research, EGT is often required to provide insight into phenomena associated with heat transfer, combustion and gas flow or for the validation of simulations of catalyst converters, Diesel Particulate Filters (DPFs) and NOx Traps [5]. In this research, the correction factor between EGT and combustion temperature was found to be 0.03 respectively. Values for exhaust gas temperatures significantly differ when the combustion air-fuel ratio is either lean or rich. When a rich combustion air-fuel ratio is considered, exhaust gas temperatures tend to either increase or decrease, depending on the fuel in use [6]. High temperatures (typically above $900^{\circ} \mathrm{C}$ ) can 
be an indicator of unfavorable conditions likely to lead to catastrophic engine failure. Under such conditions, measurement of temperature is normally a challenge as sensors to directly sit and measure temperatures in combustion cylinders would be quite expensive [6]. As such, measurement of exhaust gas temperature, at the entrance into the exhaust manifold, tends to be more ideal. Since the exhaust is a few crank angles away from the combustion cycle, measurement of its temperature is considered to be a better way of measuring combustion temperature [6]. Combustion temperatures are known to directly affect engine knock, a situation in which the air-fuel mixture ignites before spark plug ignition timing. This happens when excessive combustion temperatures lead to spontaneous lighting off of fuel after it hits the hot chamber, making the piston slam into the expanding flame front, causing a knock noise. Furthermore, exhaust gas temperatures are widely known to affect performance of catalytic converter [1]. Average exhaust gas temperatures are an important quantity for determining performance of turbochargers, catalytic converters, and particulate traps. Knowing the exhaust gas temperature can immediately help many other applications as well [7]. After an engine cold start, since catalytic a converter would not have reached its operating temperature yet, and so hydrocarbon emissions would be untreated. A study [1] appears to suggest that more than $80 \%$ of hydrocarbon emissions measured over the entire FTP-75 drive cycle, were emitted within the first 20 seconds after the engine was started. Additionally, the study was of the view that performance of catalytic converters could be optimized, if the EGT was known. This was envisaged [1] to have an immediate improvement on hydrocarbon emissions.

EGT is one of the parameters used when engine performance is to be studied indirectly. Bietresato et al. [2] studied torque prediction in a CI engine for agricultural purposes based on EGT and CFD-FVM methodologies. A CFD-FVM model of the exhaust pipe in a CI engine was used to raise the prediction capabilities of an indirect torque-evaluation model based on the EGT. CFD-FVM model, which addresses all non-linearities in the system (especially in the correlation of the EGT with the temperatures measured in other three points of the exhaust line) and their dependence on engine speed, was employed. A simple (linear) model was set up to estimate the torque, based only on the EGT. Torque estimations based on temperature tend to have a maximum absolute relative error of $2.9 \%$. Expanded uncertainty intervals are normally very close to what was determined experimentally [2]. Mohsen et al. [8] experimentally investigated EGT and delivery ratio effects on emissions and performance of a gasoline-ethanol two-stroke engine. A blended fuel of ethanol and gasoline was used to determine effects of exhaust temperature on the performance and emissions (CO, $\mathrm{HCs}, \mathrm{CO}_{2}$, NOx) of a two stroke SI engine running at different speeds and loads. Results showed increases in EGT with increase in engine speed, and a decrease in the time required for combustion, which led to an increase in CO. Generally, for different speeds and loads, CO emissions decreased by about 35\% and on each 5\% 
increase in ethanol content in the fuel blend, $\mathrm{CO}_{2}$ emissions decreased by about 6.3\%. The relatively high amount of thermal energy lost through exhaust gases forced scientists to investigate how to get benefit of this energy. One of the main parameters that affects the performance of heat recovery process is the gases temperature [8]. Hassan et al. [9] studied effects of EGT on the performance of a hybrid heat recovery system. It was noted that heat transfer rates tend to increase linearly with increases in EGT. Results appeared to further show that heat recovery offers an excellent opportunity for cost and energy saving in industrial and residential applications. It was observed that heat recovery from exhaust gases was affected by the EGT and flow rate. Effects of EGT on a proposed hybrid heat recovery system (HHRS) were studied. A domestic thermoelectric cogeneration heat recovery system was utilized in the study. It was observed that by increasing the temperature of gases, heat rate and temperatures at each layer increase linearly. Power generated by the thermoelectric generator (TEG) progressively increased with increases in EGT. It was further shown that for the utilized configuration of the HHRS, when the temperature of gases doubled, power produced increased by about 5 times [9]. Other studies [10] investigated the significance of the ratio of EGT to coolant temperature and its effect on various engine operating parameters. It was found that increasing the external load had a significant increase in the diesel load and this made the engine to work more effectively. But this increase in the load led to an increase in the exhaust temperature to coolant temperature $(\mathrm{E} / \mathrm{C})$ ratio, thus making the coolant ineffective to carry away the heat of the cylinder wall and hence helping in the cylinder wall temperature increase. Furthermore, it was noticed that the ratio of the exhaust temperature to the coolant temperature increased as the load on the engine increased. Coolant performance is normally the best when engine is running at no load condition. And its effectiveness goes on decreasing with increases in engine load. In other words, coolant will take maximum amount of heat from cylindrical walls at no load conditions, as heat absorption and transfer capacity will go on decreasing with increasing load. Results showed that the E/C ratio plays an important role in determining performance of an engine. It was demonstrated that the $\mathrm{E} / \mathrm{C}$ ratio predicts the effectiveness of the coolant. In the study, it was pointed out that the effectiveness of the coolant was predicted by the E/C ratio. Furthermore, the study was only able to predict the increase in exhaust emissions and behaviors of lubricating oil, by using the E/C ratio [10]. Generally, most previous studies did not attempt to elucidate these combustion characteristics. This is observably due to the fact that studies were mostly experimental. To fully explain engine performance characteristics, numerical simulations based on meaningful physically-based accurate models will be inevitable. These models should take into account significant chemical and physical processes taking place in an engine. Kiva4 is one of the developed codes, an advanced computational fluid dynamics (CFD) modeling code that accurately simulates in-cylinder processes of engines [11]. It is able to simulate combustion characteristics in spark ignition 
engines; such as exhaust gas temperature. In this paper, results of a study on combustion characteristics, particularly, the correlation between exhaust gas temperatures and engine speed, using the kiva4 code, are presented. Experiments to validate simulation results were conducted on a spark ignition engine. Simulations were conducted based on test conditions. The kiva4 code was able to simulate combustion characteristics, as evident from the good agreement obtained when simulations were compared with experimental results. Under the considered loading conditions, the model has shown significant predictability for combustion characteristics. Furthermore, this work is a precursor to subsequent studies which will predict combustion characteristics for fuel-blends of gasoline with selected proven mix ratios of $\mathrm{n}$-butanol with methanol. These (oxygenated) fuels have been used previously [12], as additives to gasoline in order to reduce emissions.

\section{Experimental Setup and Materials}

Experiments and measurements were performed in an engine test room in the department of Electrical Engineering at The Copperbelt University in Kitwe Zambia. The engine on which tests were conducted was mounted on a test bench and it was fitted with an air cooled eddy current dynamometer which was able to provide a maximum raw torque of $34 \mathrm{Nm}$ with a precision of $\pm 0.5 \%$. This was a Volkswagen (VW) Polo 6 TSI 1.2, three-cylinder engine manufactured by AmtecTechniquip, see Figure 1. The engine was fully equipped with a turbocharger in addition to other necessary sensors and actuators for stable operation. In this study, three experiments were conducted, and in all experiments the engine was

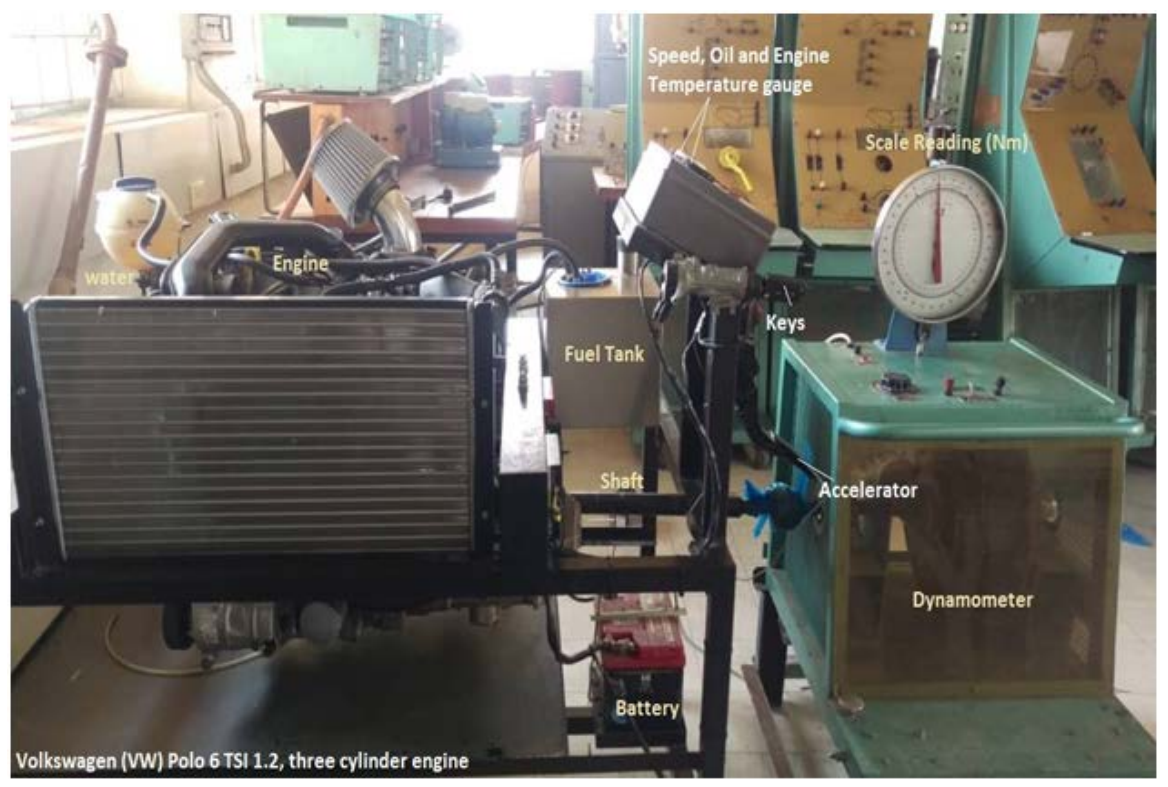

Figure 1. A three cylinder, four strokes Volkswagen (VW) Polo 6 TSI 1.2 gasoline engine. The engine specifications of the Volkswagen (VW) Polo 6 TSI 1.2, three-cylinder engine are shown in Table 1. These specifications were used both in the experiment and simulation of the engine performance. 
heated up until the temperature were about $98^{\circ} \mathrm{C}$ and the test bed kept this temperature constant. A DC/AC convertor was used to convert AC to DC for use by the dynamometer. A control panel was used to regulate the voltage supplied to the dynamometer at $20 \mathrm{~V}, 50 \mathrm{~V}, 80 \mathrm{~V}$ and $90 \mathrm{~V}$. This was done in order to control the torque generated by the dynamometer.

\subsection{Experimental Setup}

In this study, three variables were considered, and at every instant, one variable was kept constant while varying the other two. In the first experiment, variations in exhaust gas temperature were studied by keeping the engine speed constant at $2500 \mathrm{rpm}$ (as the dependent variable) whilst the load (as the independent variable) was varied. In the second and third experiment, effects of keeping the load constant at, no load and $18 \mathrm{Nm}$, on the variations in exhaust gas temperature was studied (as the dependent variable) whilst the speed (as the independent variable) was varied.

\subsection{Model Validation}

The Kiva4 package which includes a basic grid generator, K3PREP that writes a file itape17 conforming to the specification, was used to study the variations in exhaust gas temperatures when the load and the engine speed were varied [13] [14] [15]. To reduce computational time, a $45^{\circ}$ asymmetrical mesh was created based on the symmetry of the combustion chamber of Volkswagen (VW) Polo 6 TSI 1.2. After the model was developed, simulations were performed based on the input parameters of the engine [11] [12] [13]. The software is open source

Table 1. Engine specification.

\begin{tabular}{cc}
\hline Specification & Value \\
\hline Engine Type & Volkswagen (VW) Polo 6 TSI 1.2 \\
Cylinders & 1422 \\
Capacity $\left(\mathrm{cm}^{3}\right)$ & 79.5 \\
Bore $(\mathrm{mm})$ & 95.5 \\
Stroke $(\mathrm{mm})$ & 10.5 \\
Compression ratio & 4 \\
Valves (per cylinder) & $55 @ 3000$ \\
Power Output (Kw @ r $/ \mathrm{min})$ & 12.9 \\
Acceleration in seconds $(0-100 \mathrm{Km} / \mathrm{h})$ & \\
Rated speed & $2,7,18$ and 23 \\
Torque (Nm) & Direct injection \\
Fuel System & Regular \\
Catalyst &
\end{tabular}


after paying a fee; it has more than 30 years on the market and began with version 2. Right now, versions $3 \mathrm{~V}$ and 4 are still maintained by Los Alamos National Laboratory [11]. Table 2 indicates some of the specifications of the computer used while Table 3 indicates the input parameters in Kiva4 itape 5 file.

\subsection{Materials}

In the experiment, EN-91 unleaded super gasoline was used from start. In the fuel name, the number 91 refers to the octane rating. The higher the octane rating, the less likely the fuel will be to cause the knocking to occur. This is due to the fact that octanes burn slower since they have longer chained hydrocarbons and are more resistant to igniting prematurely [16]. Other properties of the fuel are indicated below in Table 4.

In order to understand the performance of the engine and how the exhaust gas temperature affects its performance, the following controls were measured.

Table 2. Computer specifications.

\begin{tabular}{cc}
\hline Internal memory & 1 Tera Bit \\
Installed memory (RAM) & $8 \mathrm{~GB}$ \\
Operating system & Ubuntu 14.04 LTS \\
System type & 64 bit \\
\hline
\end{tabular}

Table 3. Itape5 input parameters.

\begin{tabular}{cc}
\hline Parameter & Value \\
\hline Rpm & 850 (changing) \\
Cafin & 720 \\
Atdc & -46 \\
Bore & 7.95 \\
Stroke & 9.95 \\
Squish & 1.000374 \\
Thsect & 45 \\
Sector & 1 \\
Tcut & 800 \\
Tcute & 1000 \\
Calign & 364.5 \\
Cadign & 9.6 \\
Calinj & 5 \\
Cadinj & 12.672 \\
Presi & $1.629802218 \mathrm{e}+6$ \\
Tempi & 350.96 (changing) \\
Tspmas & 0.000072 (changing) \\
&
\end{tabular}


Table 4. Gasoline fuel properties.

\begin{tabular}{cc}
\hline Property & Value \\
\hline Net Lower Heating Value $(\mathrm{M} \mathrm{J} / \mathrm{kg})$ & 43.5 \\
Specific Gravity & 0.72 \\
Octane Number & 91 \\
Density $\left(\mathrm{kg} / \mathrm{m}^{3}\right)$ & 720 \\
Auto-ignition temperature $\left({ }^{\circ} \mathrm{C}\right)$ & $228-470$ \\
\hline
\end{tabular}

\subsubsection{Torque Measurement}

Engine torque was measured using an eddy current dynamometer. The engine was clamped on a test bench and the shaft was connected to the dynamometer rotor as shown in Figure 1. Operation of the engine coupled to a dynamometer through a shaft on test bench, over its load and speed range generated the torque and fuel flow rate data from which such the engine performance was observed and regulated [7]. The engine was switched on until it became stable at idle speed of $850 \mathrm{rpm}$. Slowly the engine speed increased to a higher speed than the required before the dynamometer was engaged. After the engine reached stable running state, the dynamometer was then engaged and the speed was observed to reduce. The required torque was set to $2 \mathrm{Nm}, 7 \mathrm{Nm}, 18 \mathrm{Nm}$ and $23 \mathrm{Nm}$ at a constant speed of $2500 \mathrm{rpm}$.

\subsubsection{Fuel Consumption}

The rate at which an engine uses fuel was measured by calculating the volume of the fuel being used by the engine. This was done whilst the engine was running. Before taking the first reading and the second reading, the engine had to be stopped in order to accurately take the readings before running the engine again. The engine was running for 20 minutes just after switching it on in order for it to reach a stable running state, before any readings could be taken. The fuel tank was square in shape, making it easy to determine the volume of the fuel used because the value is the difference between the initial and final readings. A calibrated rule was used to take readings. After the engine reached stable running state, the first reading was taken and a stop watch started running. This was done for each trial. There were four trials for each engine run. Each trial took duration of 10 seconds at every engine load (torque) considered.

\subsubsection{Temperature Measurements}

\section{1) Engine Temperature}

Every engine contains a cooling system that is designed to maintain a fairly constant working temperature. The actual engine temperature can vary for a number of reasons, and may even reach such levels which may damage the engine. Broadly, there are two types of engine cooling systems used for heat transfer from the engine block and head liquid cooling and air cooling [17]. Temperature gauges provide an early warning of overheating, allowing possibility to stop the engine before any damage occurs. In this study, a temperature gauge on 
the engine was used to measure and take the engine temperature readings. The range of temperature readings were from $40^{\circ} \mathrm{C}$ to $120^{\circ} \mathrm{C}$. The maximum operating temperature for the engine was found to be about $98^{\circ} \mathrm{C}$ after the engine had run for more than five hours. If the temperature exceeds this value, the engine may get damaged. To avoid this, the engine was being cooled by the water that was being circulated and addition to the air blown from the fan. Automatically, the fan was switched on when engine temperature reached $90^{\circ} \mathrm{C}$. In order to study variations in the temperature readings, engine temperatures were recorded from the start to finish every 10 seconds at every engine load (torque) considered.

\section{2) Exhaust gas temperature (EGT)}

Exhaust gas temperature, also referred to as EGT, measures the temperature of gases leaving a diesel/patrol engine exhaust manifold. Excessive exhaust gas temperatures are primarily a result of engine failure, since high temperatures can cause metal components to melt and weld together or suffer catastrophic failure [7] [18]. As such, it is important to investigate how exhaust gas temperature influence performance of engines in relation to the type of fuel used. To measure exhaust gas temperatures, a K-type thermocouple was employed and readings were taken in degrees Celsius. Figure 2 shows the thermocouple used, in this study, to measure exhaust gas temperatures.

A thermocouple, a device consisting of two dissimilar electrical conductors forming electrical junctions at different temperature, consists of a thermocouple probe and a thermocouple multi-meter. Thermocouple probes are a base metal thermocouple system using two dissimilar metals welded at the tip forming what is commonly known as a thermocouple junction. The thermocouple multi-meter was used for displaying the measured temperatures in degrees Celsius. A thermocouple produces a temperature, dependent voltage as a result of the thermoelectric effect and this voltage is then interpreted in terms of temperature. Table 5 below indicates the properties of the K-type thermocouple (Nickel chromium/ Nickel-Alumel).

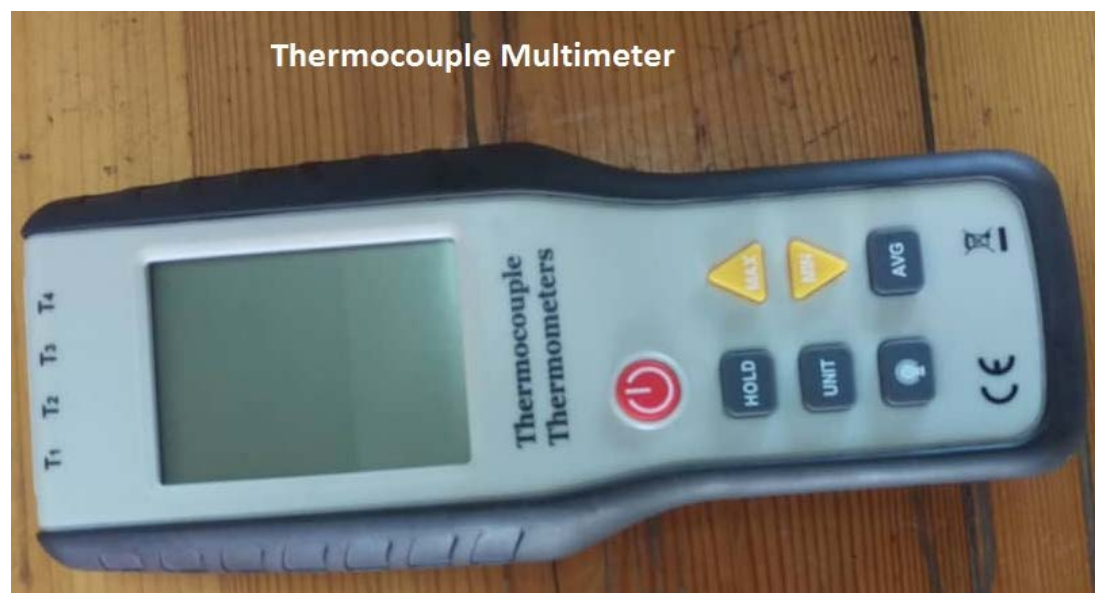

Figure 2. Thermocouple thermometers. 
Thermocouple probes were installed in the exhaust pipe of a production-type, spark ignition engine. The engine had 3 cylinders with a swept volume of 1422 $\mathrm{cm}^{3}$, as shown in Figure 3.

To avoid effects of radiation on the thermocouple, it was mounted on the external surface of the work bench far from the exhaust manifold. Probes were mounted on the exhaust pipe closer to the exhaust valves in order to get accurate temperature readings [19]. On the exhaust pipe, there is an $8 \mathrm{M}$ screw which goes inside the exhaust pipe. When the screw was removed, there is approximately a $130 \mathrm{~mm}$ hole. A different but similar in size and screw threads, was used to replace the $8 \mathrm{M}$ screw, which was exactly as the original screw. A $3 \mathrm{~mm}$ hole in diameter was drilled inside the screw where the probe was to be placed. The filling material called gun gum was used to seal the remaining parts of the probe because the gun gum hardens when heat is applied.

The probe is $100 \mathrm{~mm}$ long and $3 \mathrm{~mm}$ wide, $50 \mathrm{~mm}$ was placed inside the exhaust pipe. Figure 4 below shows how the thermocouple probe was placed relative to the exhaust valves. In the first experiment: at a constant speed of 2500 rpm, measurements were taken every 10 minutes. This was because the EGT could only stabilize after every 10 minutes and not before, then it would later start to increase again. The second experiment was in two parts-the first was for no load whilst changing the speed. Here, measurements were taken every 1 minute until the engine reached a stable running state. When the engine reached

Table 5. Properties of a K-type thermocouple [20].

\begin{tabular}{cc}
\hline Thermocouple (type) & K-type \\
Temperature range & $-200^{\circ} \mathrm{C}$ to $1350^{\circ} \mathrm{C}$ \\
Accuracy & $\pm 2.2 \mathrm{C}$ or $\pm 0.7 \%$ \\
Limits of error & $\pm 1.1 \mathrm{C}$ or $\pm 0.4 \%$ \\
Sensitivity & Approximately $41 \mu \mathrm{V} /{ }^{\circ} \mathrm{C}$ \\
\hline
\end{tabular}

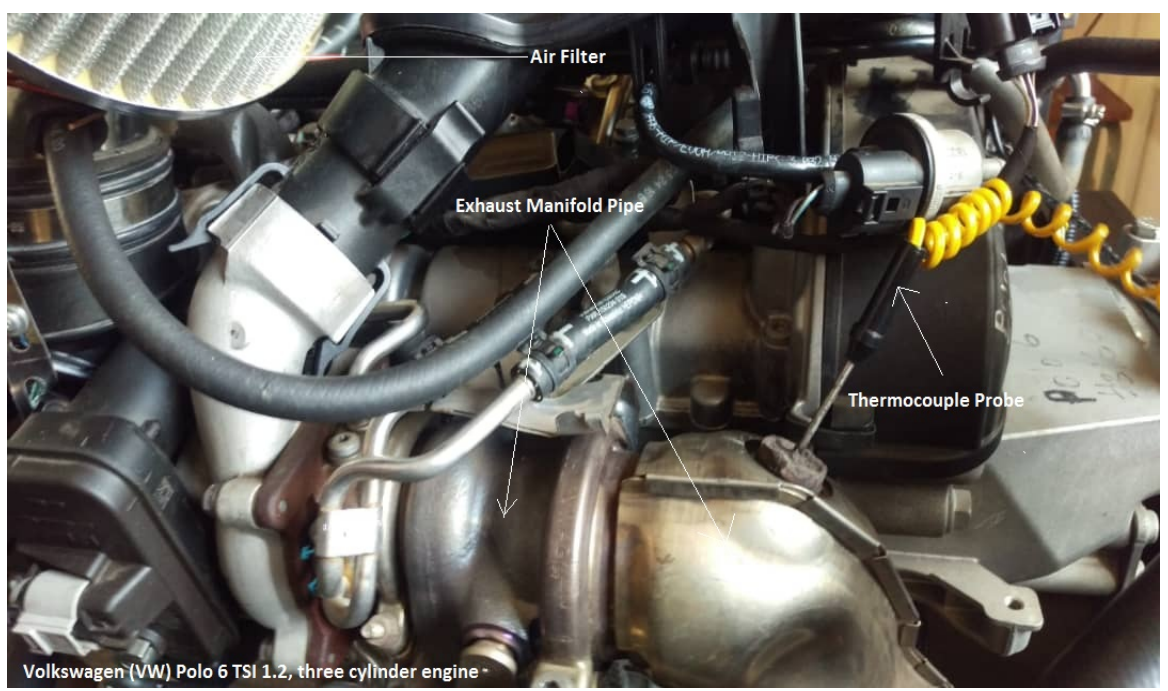

Figure 3. Exhaust manifold where the thermocouple was installed. 


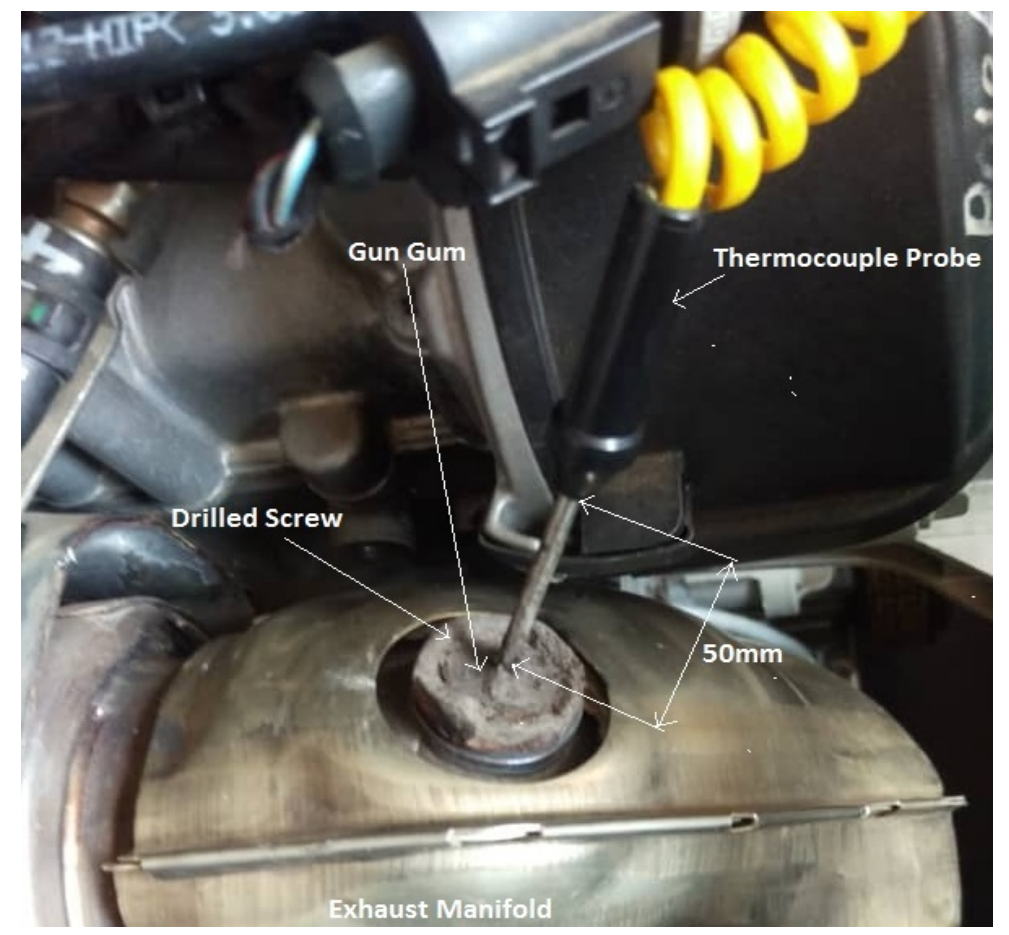

Figure 4. Thermocouple installation.

a stable running state, speed was then increased starting from idling (which was at a speed of $850 \mathrm{rpm}$ ) to $1000 \mathrm{rpm}, 1500 \mathrm{rpm}, 2000 \mathrm{rpm}$ and finally to 2500 $\mathrm{rpm}$. The engine would then run for an hour to reach a stable running state, but slowly reducing time for each speed until the last speed which took only $10 \mathrm{mi}-$ nutes for the engine to reach a stable running state. In the second part, at a constant load and slightly changing the speed, measurements were taken every 10 seconds.

\subsection{Dyno Correction Factor}

The engine generates different power output on different days depending on atmospheric conditions. Excluding other factors like engine temperature and quality of fuel used, the engine output power is very dependent on the amount of oxygen in the air. So the only way to study an engine's horsepower is to correct the output on a given day to some standard. Furthermore, engine power and torque available from a normally aspirated internal combustion engine are dependent upon the density of the air, higher density means more oxygen molecules and more power, lower density means less oxygen and less power. The dyno correction factor was used to determine the standard raw power and raw torque. Dyno correction factor is a mathematical reciprocal of the relative horsepower. One of the most important uses of the dyno correction factor is to make the horsepower and torque values standard. This is done in order to remove the effects of ambient conditions, temperature and pressure. As such, this factor is used to normalize the power and torque values taken under different conditions. That is, the normalized values are the same as those taken under controlled en- 
vironmental conditions (temperature, pressure and humidity), considered as standard power and torque. It is sometimes used to understand how much power is developed on a specific day due to the temperature, humidity and pressure on that day. Hence, the uncorrected power is used to take the readings [21]. Correction factors are available to predict the power developed by the engine under distinct ambient conditions from the engine power curve obtained in laboratory tests at a standard condition [22]. But when determining much more power due to the new headers, or the new cam, the corrected power is more useful, since it removes the effects of atmospheric conditions and just shows how much more (or less) power there is than in the previous tests. The society of automotive engineers (SAE) created the SAE J1349 JUN90 standard method for correcting horsepower and torque readings so as to make readings conform to the same "standard" test cell where the atmospheric conditions are kept constant. Furthermore, the SAE J1349 JUN90 standard includes an assumed mechanical efficiency of $85 \%$ in order to provide an estimate of the true engine horsepower (without accessories).The equation for the dyno correction factor given in SAE J1349 JUN90 (for normally aspirated gasoline engines), converted to use pressure in $\mathrm{kPa}$, is [21]:

$$
c_{f}=1.180\left[\left(\frac{99}{P_{d}}\right) \sqrt{\left(\frac{T_{c}+273}{298}\right)}\right]-0.18
$$

where: $c_{f}=$ the dyno correction factor,

$P_{d}=$ the pressure of the dry air, in $\mathrm{kPa}$,

$T_{c}=$ ambient temperature, ${ }^{\circ} \mathrm{C}$.

In this study, pressure of dry air was measured using a barometer while the ambient temperature was measured using a multi-meter or thermocouple multimeter. The barometer readings showed a pressure of the dry air to be about $101.325 \mathrm{kPa}$, while the ambient temperature was $30^{\circ} \mathrm{C}$. Therefore, using Equation (1), $c_{f}=0.9924$.

\section{Results and Discussion}

\subsection{Results Obtained in the First Experiment}

In the first experiment, engine speed was kept constant while varying load (torque). This was done in order to obtain power generated by the engine and evaluate other performance characteristics of the engine. Engine torque, fuel consumption and exhaust gas temperature were measured at a constant engine speed of $2500 \mathrm{rpm}$. Engine performance parameters are used to evaluate the performance of engines, comparative assessment of engines and to determine the general characteristics of an engine. In this study, to investigate the performance of an engine, a three-cylinder engine was employed to conduct experimental studies. Performance parameters such as power, fuel consumption and exhaust gas temperature were examined over a range of values of torque. Effects of varying the load (torque) on power are shown in Figure 5. It is clear from the graph 


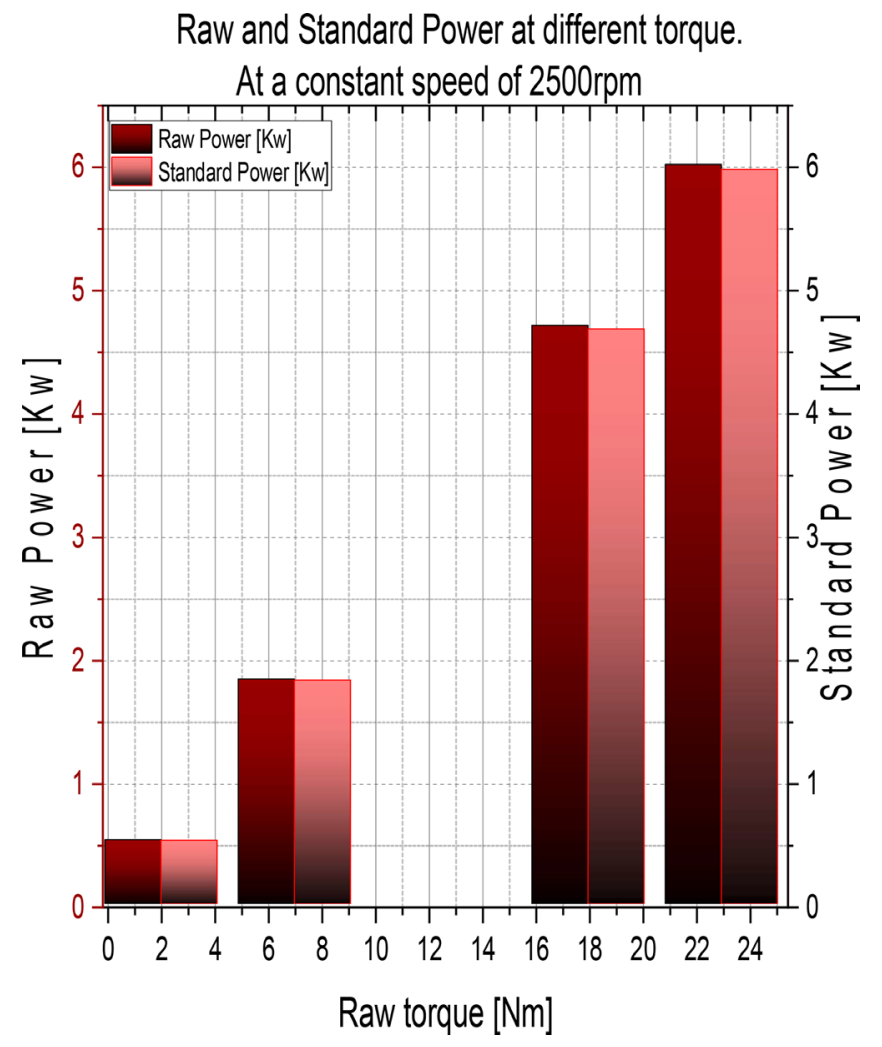

Figure 5. Raw and standard power at different torque.

that the power generated by the engine was continuously increasing with the increase in torque. At any layer in the system, a linear increase in power with increase in torque is observable. A load of $2 \mathrm{Nm}$ generated power of about 0.524 $\mathrm{kW}$, while a load of $23 \mathrm{Nm}$ generated power of about $6.02 \mathrm{~kW}$. Effects of variation in torque on specific fuel consumption, at constant engine speed, were looked into. From Figure 6, it was observed that at $2 \mathrm{Nm}$ the specific fuel consumption was about $496.18 \mathrm{~g} / \mathrm{kWh}$. Results show that the specific fuel consumption increased with increase in torque. The minimum fuel supplied to the engine was $439.49 \mathrm{~g} / \mathrm{kWh}$ at $18 \mathrm{Nm}$ while the maximum fuel supplied is $694 \mathrm{~g} / \mathrm{kWh}$ at 7 $\mathrm{Nm}$. This implies that with an increase in power and torque, the specific fuel consumption increases until it starts to reduce, thereby increasing the efficiency of the engine. The specific fuel consumption is a parameter that reflects the efficiency of a combustion engine which burns fuel and produces rotational power at the shaft or crankshaft [23]. It is mainly dependent on engine speed, power and the type of fuel used. Even though other factors affect fuel consumption, like ignition timing, injection timing, compression ratio etc., the more fuel is supplied into the engine, the more is the generated power. The Raw SFC is 0.9942 more than the Standard SFC but between $8 \mathrm{Nm}$ and $18 \mathrm{Nm}$ the results are the same.

The study furthermore investigated the effects of changing the torque on the brake thermal efficiency. Results of this study are presented in Figure 7. The brake thermal efficiency (BTE) is mainly based on the brake power of the engine. 


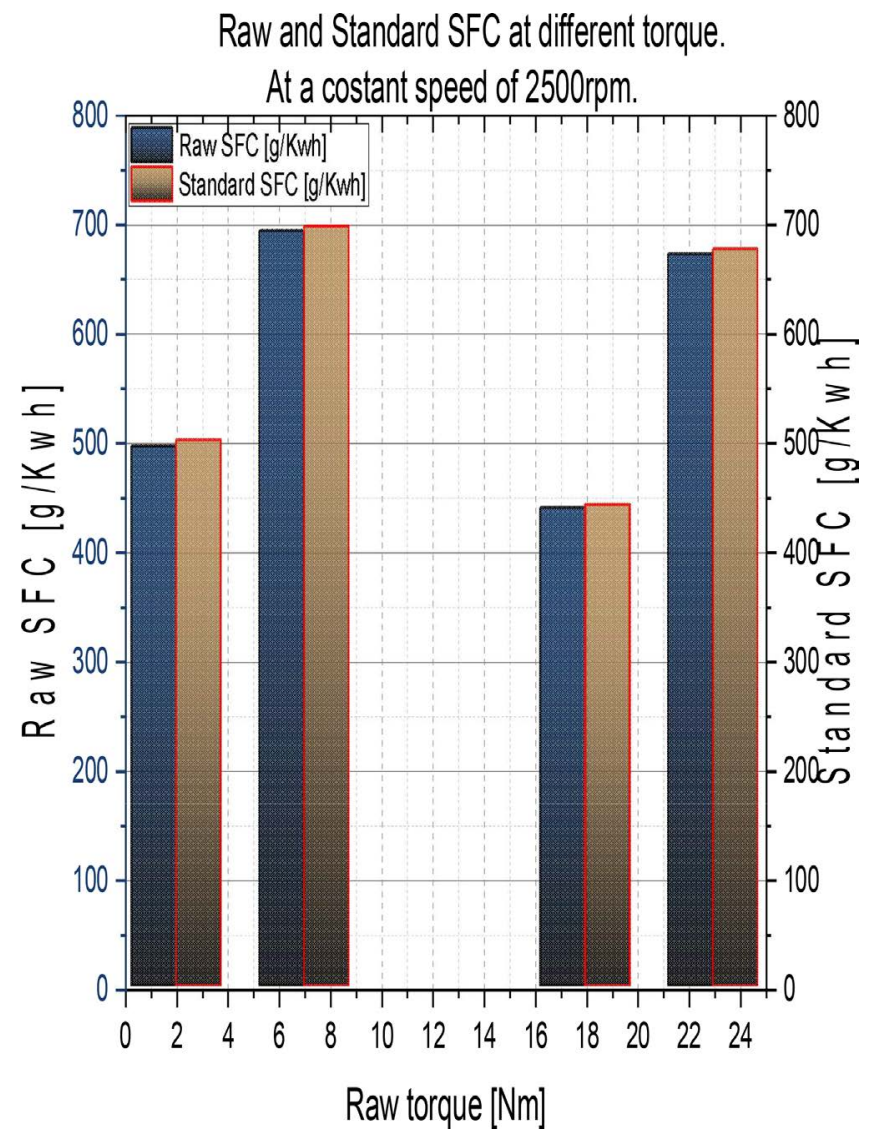

Figure 6. Raw and standard SFC at different torque.

Raw and Standard BTE at different torque.

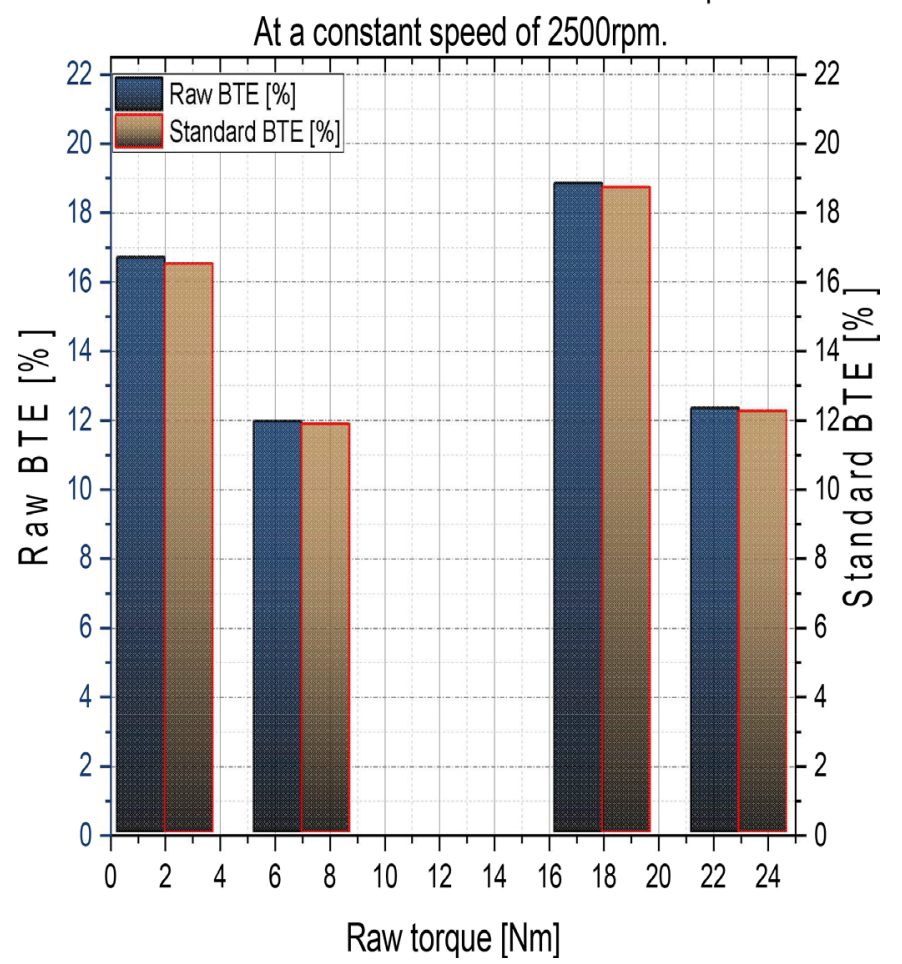

Figure 7. Raw and standard BTE at different torque. 
The efficiency gives an idea of the output amount of power generated by the engine with respect to heat supplied in the form of fuel. The maximum and minimum brake thermal efficiency of the engine was $19 \%$ at $18 \mathrm{Nm}$ and $12 \%$ at 7 $\mathrm{Nm}$, as shown from Figure 7. This mainly implies that the combustion temperature in the combustion chamber is higher at $18 \mathrm{Nm}$ than at $7 \mathrm{Nm}$. At the same time, the high combustion temperature in the combustion chamber reduces the amount of fuel consumption which improves the thermal efficiency of the engine. The amount of power generated increases with increase in combustion temperature. The Raw BTE is 0.9924 more than the Standard BTE but between 8 $\mathrm{Nm}$ and $18 \mathrm{Nm}$, they were very close. Effects of variations in torque on exhaust gas temperature (EGT), at a constant engine of $2500 \mathrm{rpm}$, was investigated and results are presented in Figure 8. The graph, in Figure 8, shows that measurements of the exhaust gas temperature started at $2 \mathrm{Nm}$ at which the EGT was about $210^{\circ} \mathrm{C}$. At this point, the engine had been warmed up and had reached a stable running state, for analysis. The exhaust gas temperature continued to increase as the power and torque of the engine increased. The maximum exhaust gas temperature was $264^{\circ} \mathrm{C}$ at a load of $23 \mathrm{Nm}$.

With this amount of temperature, the catalytic converter on the engine starts to function. The temperature of the exhaust gases should be at least between $250^{\circ} \mathrm{C}$ to $300^{\circ} \mathrm{C}$ for the catalytic converter to function properly. As the exhaust gas temperature increases, the combustion efficiency also increases and it is at this temperature that the catalytic converter is able to function at its highest efficiency.

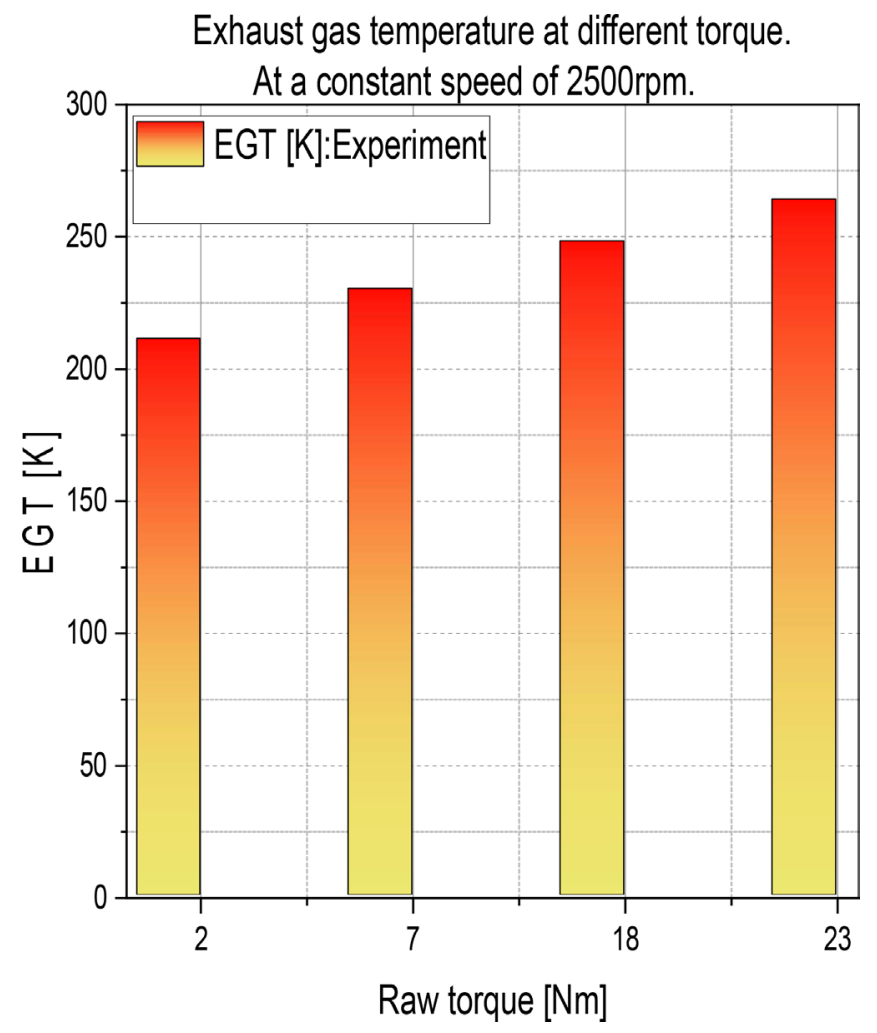

Figure 8. Exhaust gas temperature at different torque. 


\subsection{Numerical Modeling of EGT in Kiva4}

Numerical modeling was carried out using the computational fluid dynamics software Kiva4 code. This is a computer code for numerical modeling of transient, two and three dimensional chemically reactive flows with sprays. It uses a time-marching, finite-volume scheme which solves the conservation equations of mass, momentum, energy and accounts for turbulence using an Arbitrary Lagrangian Eulerian (ALE) method in three solution phases. To optimize computational resources, simulations were carried out using a $45^{\circ}$ asymmetrical mesh created based on the symmetry of the combustion chamber of the Volkswagen (VW) Polo 6 TSI 1.2. After the model was developed using kiva4, simulations were performed based on the input parameters shown in Table 2. The software was used to view the in-cylinder turbulent processes and heat transfer [24] Comparison between the exhaust gas temperature from the model and measured experimental results showed a qualitative closeness. Experimental results are approximately $0.02 \%$ or $2 \%$ more than results from simulations with Kiva 4 .

Recent improvements in the code's ease-of-use and versatility, for many applications, allow all the required geometrical specifications, initial conditions, and boundary conditions to be specified using the standard input alone. This is particularly true for internal combustion engine applications. Mesh generation logic allows the computational region to include cupped pistons and domed cylinder heads and, to also offset these relative to the axis of the cylinder. In addition to the two- and three-dimensional Cartesian coordinate systems and cylindrical mesh types, the code allows the simulation of the flow in a single "sector" of certain three-dimensional cylindrical configurations in which there is $\mathrm{n}$-fold symmetry about the axis of the cylinder [25]. All these factors have significant effects on the combustion process and the generated exhaust temperature results. EGT can rightfully be assumed as an indicator of possible malfunctions involving all engine performance parameters related to the engine or to the technical devices relying on EGT (the turbocharger, every pollutant-abatement system: EGR, DPF, SCR, catalytic converters etc). In particular, the relation between EGT and engine torque is very important, and it is one of the reasons why EGT is an important parameter to be gathered. Torque is a difficult parameter to measure if there are no in-built sensors. Nevertheless, its direct or indirect acquisition is fundamental as it describes engine output better than other parameters. One way around this is to derive the torque from the EGT which is measured by the use of thermocouples (TC). TCs are relatively inexpensive and tend to be user-friendly in comparison with traditional torque-metering systems [2].

Simulations were performed based on input parameters established from the conducted experimental study on the Volkswagen (VW) Polo 6 TSI 1.2 engine at no load and at $18 \mathrm{Nm}$ load. The engine was running at an idling speed of 850 rpm for some few minutes until it stabilized. Measurements were taken at variable fuel mass injection in the combustion chamber and the resulting exhaust gas temperature through the exhaust valve, at the exhaust port exited during the ex- 
haust process. This was done under different engine speeds for a gasoline spark ignition engine. Fuel consumptions and exhaust gas temperature readings were taken for two hours, at engine speeds of $850 \mathrm{rpm}, 1000 \mathrm{rpm}, 1500 \mathrm{rpm}, 2000$ rpm and $2500 \mathrm{rpm}$. Exhaust gas temperature readings were taken at no load with changes in engine temperatures of $351 \mathrm{~K}, 358 \mathrm{~K}, 368 \mathrm{~K}$ and $371 \mathrm{~K}$. For $20 \mathrm{mi}-$ nutes at engine speeds of $2000 \mathrm{rpm}, 2050 \mathrm{rpm}, 2100 \mathrm{rpm}, 2150 \mathrm{rpm}, 2200 \mathrm{rpm}$ and $2500 \mathrm{rpm}$, exhaust gas temperature measurements were read at a load of 18 $\mathrm{Nm}$ with changes in engine temperature of $365 \mathrm{~K}, 367 \mathrm{~K}, 369 \mathrm{~K}, 370 \mathrm{~K}, 371 \mathrm{~K}$ and $371 \mathrm{~K}$. It was observed that the exhaust gas temperature was mainly affected by engine speed, load and fuel mass flow injected into the combustion chamber. The thermodynamic state (temperature and pressure) of the gas in the cylinder varied continually during the exhaust blowdown phase, until the cylinder pressure closely approached the exhaust manifold pressure. In the real exhaust process, exhaust valves restrict the flow of gases out of the cylinder, the valve lift varies with time and the cylinder volume changes during the blowdown process but the principle remain the same [7]. Generally, the combustion process produces a lot of heat which causes cylinder wall temperatures to increase significantly. This heat is only removed by a coolant. Temperature of the exhaust plays an important role by giving an indication of the state of functioning of various engine parts and the engine as a whole. With increase in the load, exhaust temperatures tend to increase and leading to a corresponding coolant temperature increase. The engine cylinder remains at constant temperature at specific constant load and engine speed. For the engine to constantly work, this is also helped by constant rate of heat transfer by the coolant. With the increase in external load on the engine, power required to give the same work out put increases. As the engine load is increased exhaust temperatures also increase, this is due to a decreased rate of heat transfer through the cylinder wall at higher load [10].

\subsubsection{Comparison between Experimental and Simulation Results at no Load}

In the second experiment, engine speed was subjected to variations whilst running at no load. This was done in order to study the effects of speed variations on engine exhaust gas temperature, when the engine was at no load. Engine speeds of $850 \mathrm{rpm}, 1000 \mathrm{rpm}, 1500 \mathrm{rpm}, 2000 \mathrm{rpm}$ and $2500 \mathrm{rpm}$ were considered when obtaining exhaust gas temperature of the engine. Simulations were then performed based on the obtained experimental results. A comparison between experimental and simulations results using Kiva4 under varying engine speeds are shown in Figure 9. The graph, in Figure 9, shows that the exhaust gas temperature increases with an increase in engine speed. This increase in exhaust gas temperature was a result of an increase in the air and fuel mixture when engine speed was increased. This increase in air and fuel mixture led to an increase in the power generated by the engine which then increased the work output. The pressure in the inlet manifold varies during each cylinder intake process due to piston velocity variation, valve open area variation and the unsteady gas-flow 


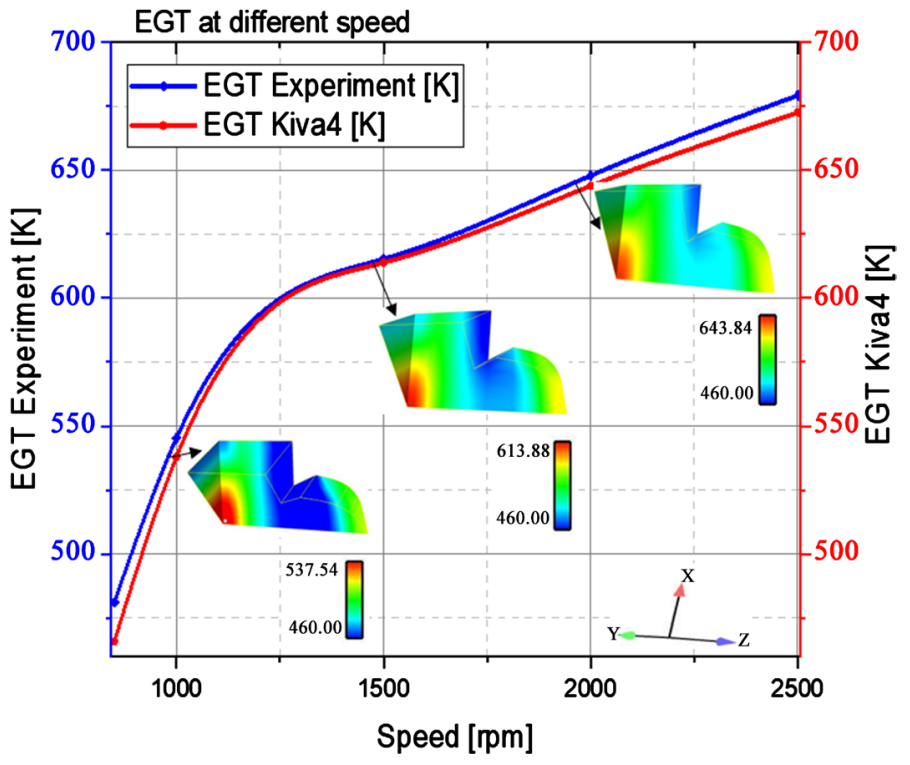

Figure 9. Combustion characteristics for EGT against speed variation for no load.

effect that result from these geometric variations. The mass of the air inducted into the cylinder and hence the volumetric efficiency, is almost entirely determined by the pressure level in the inlet port, during the short period before the inlet valve is closed. At higher engine speeds, the inertia of the gas in the intake system as the intake valve was closing increased the pressure in the port and continued the system charging process as the piston slowed down around bottom center and started the compression stroke. This effect became progressively greater as the engine speed was increased, and resulted in an increase in exhaust gas temperature. The inlet valve was closed at $46^{\circ}$ after the bottom center. From the graph, in Figure 9, experimental exhaust gas temperatures at $850 \mathrm{rpm}, 1000$ rpm, $1500 \mathrm{rpm}, 2000 \mathrm{rpm}$ and $2500 \mathrm{rpm}$ were $481 \mathrm{~K}, 545 \mathrm{~K}, 615 \mathrm{~K}, 647 \mathrm{~K}, 679 \mathrm{~K}$ while for simulations with the Kiva 4 code, these were $466 \mathrm{~K}, 538 \mathrm{~K}, 614 \mathrm{~K}, 644 \mathrm{~K}$ and $673 \mathrm{~K}$.

The exhaust gas combustion characteristic shows an asymmetrical sector with exhaust gas temperature variations. At the far left end is the bottom dead center and at the far right end is the top dead center. The temperature is mostly high in the middle of the combustion chamber and at the top dead center where the valves open to remove exhaust gases. At $1000 \mathrm{rpm}$ in the results from the kiva4 code, the exhaust gas temperature is $538 \mathrm{~K}$ as seen in red (Figure 9). At 2000 $\mathrm{rpm}$ and $2500 \mathrm{rpm}$, the exhaust gas temperature increases to $614 \mathrm{~K}$ and $644 \mathrm{~K}$. The color slowly changes with increase in temperature from dark blue to light blue as minimum exhaust gas temperature and red as maximum exhaust gas temperature. A comparison between results from the experimental study and simulations with the Kiva4 code considering variations in crank angle at different engine speeds of $850 \mathrm{rpm}$ and $1000 \mathrm{rpm}$, are shown in Figure 10(a). The exhaust gas temperature increase slightly when the engine is running at no load, typically, this measures the engine losses and residual torque at the crankshaft. This 

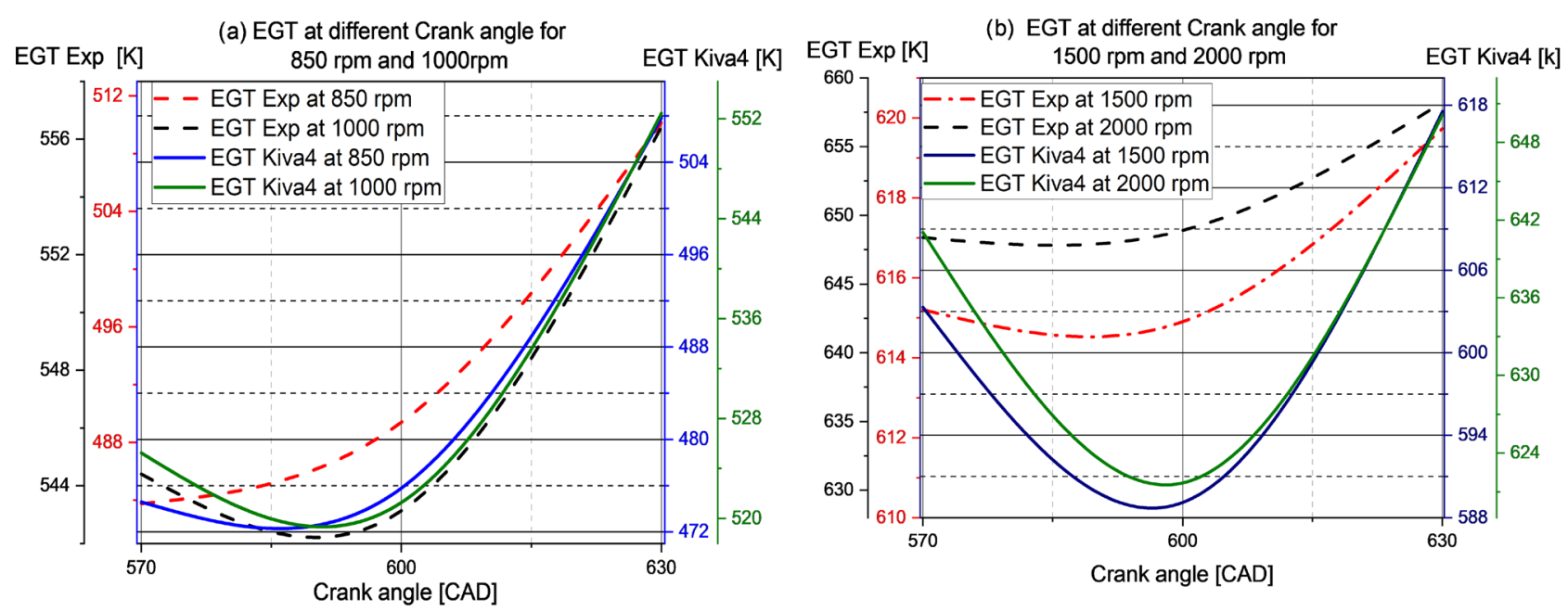

(c) EGT at different Crank angle for

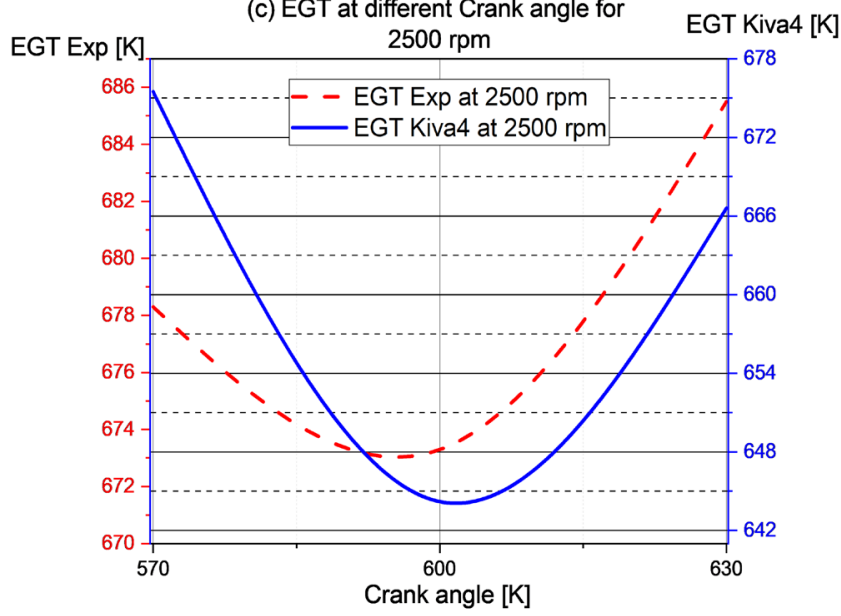

Figure 10. Exhaust gas temperature at different Crank angle of $850 \mathrm{rpm}, 1000 \mathrm{rpm}, 1500 \mathrm{rpm}, 2000 \mathrm{rpm}$ and $2500 \mathrm{rpm}$ for no load

is the lower extreme of the engine capability map and fuel injected is the bare minimum for the engine to sustain a given speed without any external load. Combustion normally tends to increase cylinder-wall temperatures. Ideally, 30\% of this heat is lost to exhaust gas while $35 \%$ is used in doing work and $35 \%$ is lost as heat through the cylinder walls. Now with the increase in the external load (current or weight) on the engine, amount of power required to do the same work increases. This leads to increased engine work and therefore increased fuel combustion per unit time. This in turn leads to a rapid increase in the temperature of the cylinder. The increase in cylinder temperature is reflected in the increase of exhaust temperature [10].

On the other hand, Figure 10(b) and Figure 10(c) show comparisons between the same parameters, at engine speeds of $1500 \mathrm{rpm}, 2000 \mathrm{rpm}$ and $2500 \mathrm{rpm}$. At 570 crank angle degrees (CAD) the engine was in the exhaust exchange process as the exhaust gas temperature slightly reduced to a minimum level at $600 \mathrm{CAD}$. The exhaust gas temperature then increased at $630 \mathrm{CAD}$ to a maximum level at 720 CAD where the valves closed. The exhaust gas temperature constantly increased as the speed increased from $850 \mathrm{rpm}$ to $2500 \mathrm{rpm}$. The exhaust gas tem- 
perature was between $510 \mathrm{~K}$ at $850 \mathrm{rpm}$ and $686 \mathrm{~K}$ at $2500 \mathrm{rpm}$ for the experiment while for simulations with the Kiva 4 code, $508 \mathrm{~K}$ at $850 \mathrm{rpm}$ and $667 \mathrm{~K}$ at $2500 \mathrm{rpm}$.

\subsubsection{Comparison between Experimental and Simulation Results at 18 $\mathrm{Nm}$}

The exhaust temperature has a direct relation with the engine load, therefore an increase in the engine load tends to raise the exhaust temperature [26]. In the third experiment, engine speed was varied whilst the engine load was kept constant at $18 \mathrm{Nm}$. In comparison to the experiment in 3.2.1 where the engine was not loaded, this was aimed at studying effects of varying engine speed on engine exhaust gas temperature when the engine is loaded. Engine speeds of $2000 \mathrm{rpm}$, $2050 \mathrm{rpm}, 2100 \mathrm{rpm}, 2150 \mathrm{rpm}, 2200 \mathrm{rpm}$ and $2500 \mathrm{rpm}$ were considered in the study. Results of this study are shown in Figure 11, where effects of varying engine load and speed on the exhaust port exit temperatures. Engine load was an external restraining torque that was being applied to the engine. Simulations were then performed, with the Kiva4 code, based on the obtained experimental results. A comparison between experimental results and simulations was made, at engine speeds of $2000 \mathrm{rpm}, 2050 \mathrm{rpm}, 2100 \mathrm{rpm}, 2150 \mathrm{rpm}, 2200 \mathrm{rpm}$ and $2500 \mathrm{rpm}$. The load was kept constant at $18 \mathrm{Nm}$ whilst varying the engine speed. Results showed that adding a load of $18 \mathrm{Nm}$ to the engine increased the fuel mass flow rate and thereby increasing the exhaust gas temperature in the combustion chamber. Increasing engine speed raised the gas temperature throughout the exhaust process. Loading the engine increased the amount of exhaust gas temperature in a short period of time.

The gas temperature in the combustion chamber increased rapidly when the engine speed and load were increased, at the same time. Increasing the load significantly means increasing the air and fuel intake, which resulted in an increase

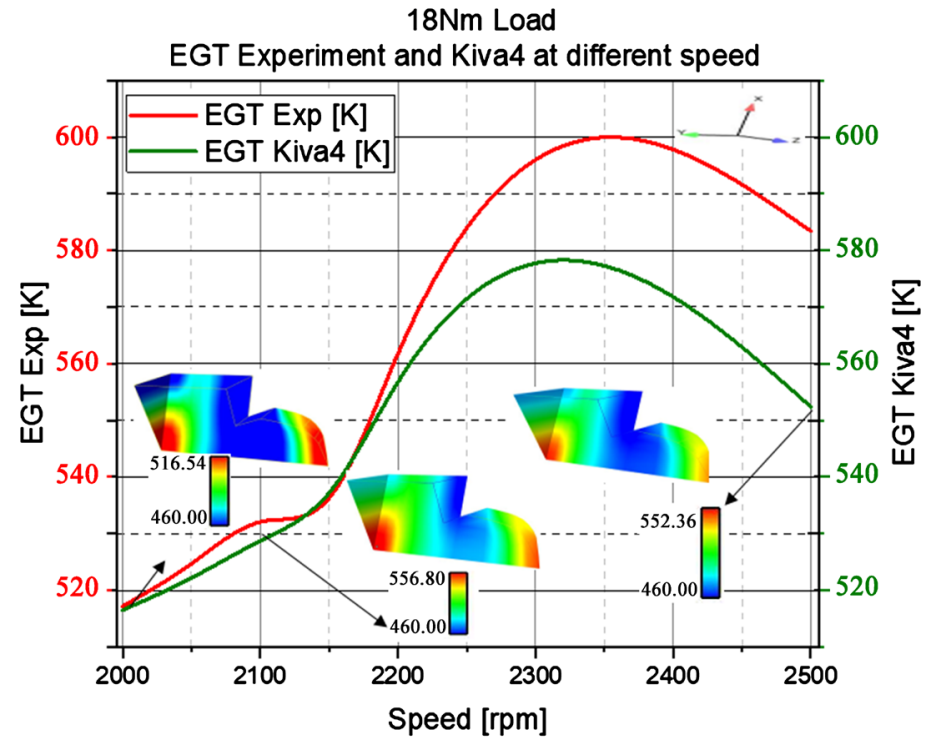

Figure 11. Combustion characteristics for EGT against speed variation for $18 \mathrm{Nm}$ load. 
in engine speed. This was attributed to the need to maintain a stable engine operating condition. More air and fuel caused more energy to be released and thus the engine provided more power which resulted in increased thermal energy. Furthermore, it was observed that whenever the load on an engine was increased, a decrease in the engine speed resulted. To compensate for this loss, in engine speed, more fuel and air was supplied to the engine. With respect to increases in the engine load, EGT increases linearly. When the engine is operated at higher loads and speeds, fuel supply (chemical energy) increases this result in an increased output of thermal and mechanical energy. This, also, leads to increased EGT. Additionally, as the load is increased, there is a corresponding increase in spark retard, which also results in increased temperatures [27].

A comparison between results from experimental investigations and simulations using the Kiva4 code, where a varying with crank angle was considered at a constant engine load engine of $18 \mathrm{Nm}$ running at engine speeds of $2000 \mathrm{rpm}$ and $2050 \mathrm{rpm}, 2100 \mathrm{rpm}, 2150 \mathrm{rpm}, 2200 \mathrm{rpm}$ and $2500 \mathrm{rpm}$. The exhaust gas temperatures were $474 \mathrm{~K}$ at $2000 \mathrm{rpm}$, and $575 \mathrm{~K}$ at $2500 \mathrm{rpm}$, for the experiment

(a) $18 \mathrm{Nm}$ Load

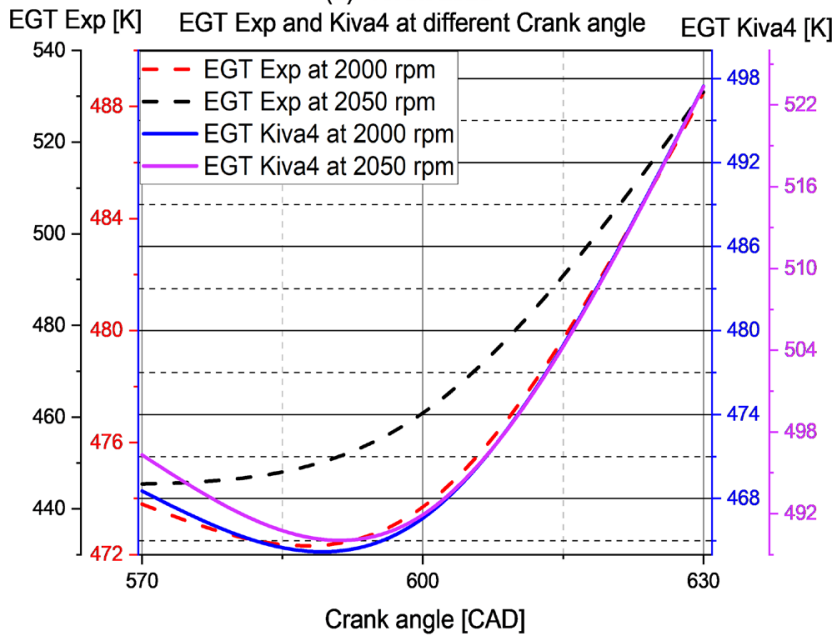

(b) $18 \mathrm{Nm}$ Load

EGT Exp [K] EGT Exp and Kiva4 at different crank angle EGT Kiva4 [K]

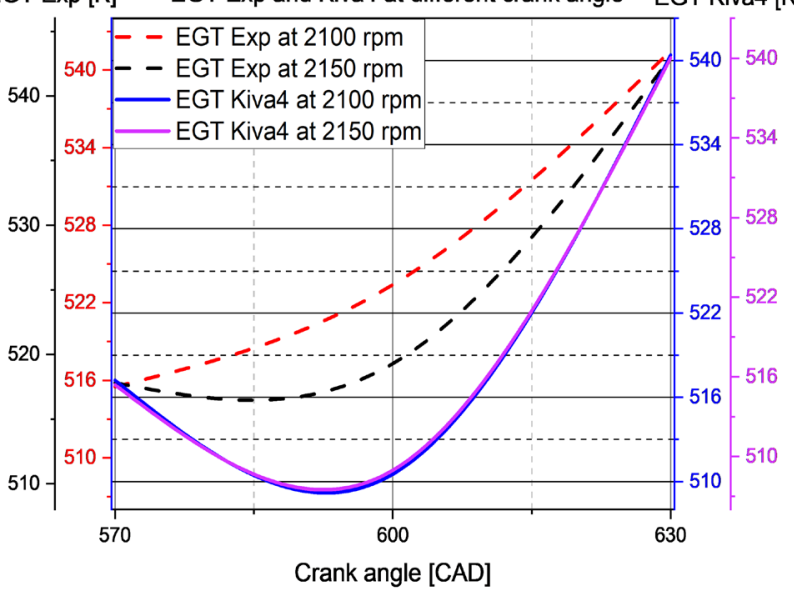

(c) $18 \mathrm{Nm} \mathrm{Load}$

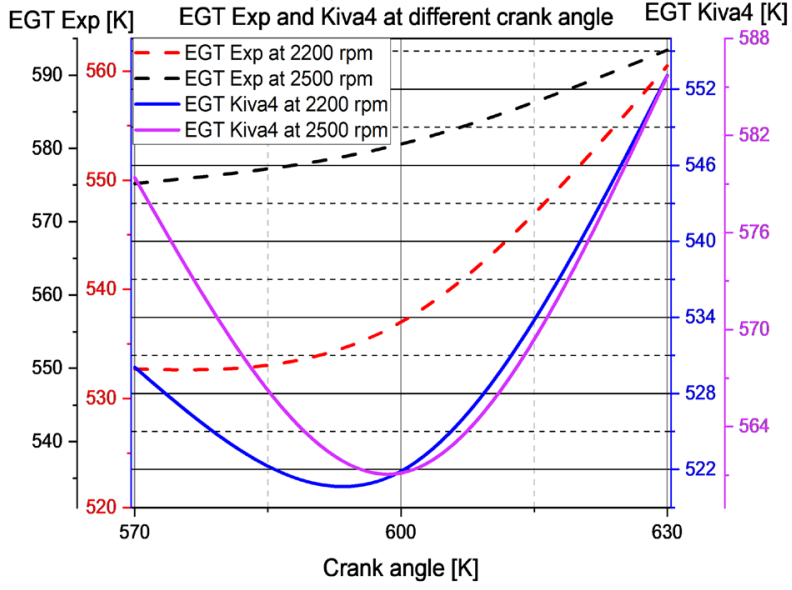

Figure 12. Exhaust gas temperature against crank angle, at different speeds of $2000 \mathrm{rpm}, 2050 \mathrm{rpm}, 2100 \mathrm{rpm}, 2150 \mathrm{rpm}, 2200$ rpm and $2500 \mathrm{rpm}$ for $18 \mathrm{Nm}$ load. 
while those for simulations with the Kiva 4 code, were $469 \mathrm{~K}$ at $2000 \mathrm{rpm}$ and 579 $\mathrm{K}$ at $2500 \mathrm{rpm}$. The exhaust gas temperature varied substantially through the exhaust process and decreased due to heat losses as the gas flowed past the exhaust valve and through the exhaust system. The average cylinder, gas temperature falls during blowdown and continues to fall during the exhaust stroke due to heat transfer to the cylinder walls. The gas temperature at the port exit at the start of the exhaust flow pulse is a mixture of hotter gas which has just left the cylinder and cooler gas which left the cylinder at the end of the previous exhaust process and has been stationary in the exhaust port while the valve has been closed. During the blow down phase, the exhaust gas is displaced and the gas comes momentarily to rest while losing a substantial fraction of its thermal energy to the exhaust port walls [7]. (Figure 12)

\subsection{Effect of Engine Speed on Fuel Mass Injected and Exhaust Gas Temperature}

As observed from Table 2, the value for Tspmas changed with changes in engine speed and temperature. In modeling with the Kiva4 code, Tspmas specified the total spray mass of fuel to be injected into the combustion chamber for pulsed sprays (i.e. reciprocating engines), or specified the fuel injection rate for continues sprays. During the compression stroke, liquid gasoline is sprayed into the cylinder from an injector with a single half sine wave, located close to the axis [13], [25]. Injection begins at $5^{\circ}$ after top dead center with duration of $12.672^{\circ}$. The injector supplies $0.000072 \mathrm{~g}$ (changeable) of fuel in the form of a hollow cone spray.

A relationship between the injected fuel mass and the exhaust gas temperature at different engine speeds for no load and $18 \mathrm{Nm}$ load, was investigated. Results are shown in Figure 13. It was observed that as the speed increased, both mass of fuel injected in the combustion chamber and the exhaust gas temperature increased. From Figure 13(a), the engine is at an idle speed of $850 \mathrm{rpm}$ and was consuming about $0.000072 \mathrm{~g}$ of fuel. As the speed increased to $1000 \mathrm{rpm}, 1500$ $\mathrm{rpm}, 2000 \mathrm{rpm}$ and $2500 \mathrm{rpm}$, mass of fuel injected correspondingly increased to $0.00196 \mathrm{~g}, 0.004 \mathrm{~g}, 0.0044 \mathrm{~g}$, and $0.006 \mathrm{~g}$, respectively. The increase in mass of fuel had a significant impact on the thermal energy and power generated by the engine. Figure 13(c) and Figure 13(d), show the effect of loading the engine whilst varying the engine speed, on mass of fuel injected. At $2000 \mathrm{rpm}$ the mass of fuel is $0.0029 \mathrm{~g}$ and increases to $0.0031 \mathrm{~g}$ at $2050 \mathrm{rpm}$. It is evident that the mass of fuel mass reduces to a minimum value of $0.0029 \mathrm{~g}$ and then continues to increase to $0.0031 \mathrm{~g}$ and finally to 0.0055 at $2500 \mathrm{rpm}$.

\section{Conclusion}

In this paper, spark ignition gasoline engine combustion characteristics were investigated. Particularly, a correlation between engine speed, load and exhaust gas temperature was studied by experimental and numerical simulations, using the 
(a) No Load

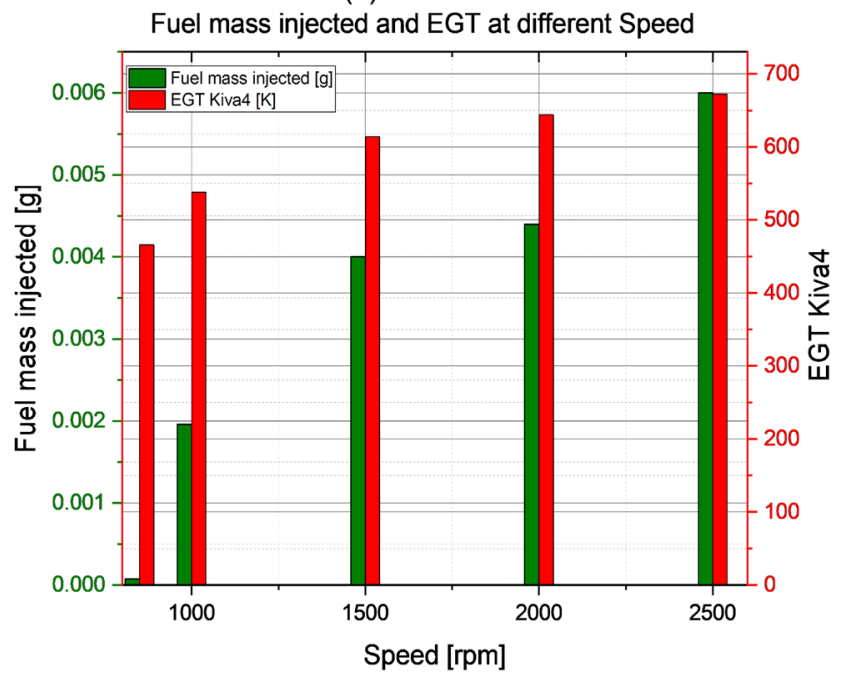

(c) $18 \mathrm{Nm}$ Load

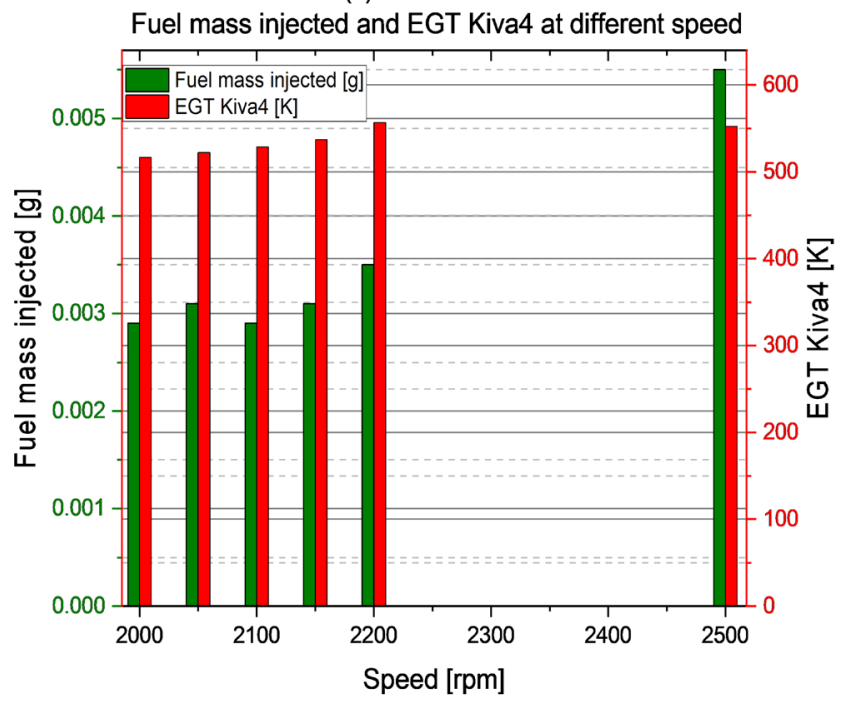

(b) Fuel mass injected and EGT Kiva at

diffrerent speed

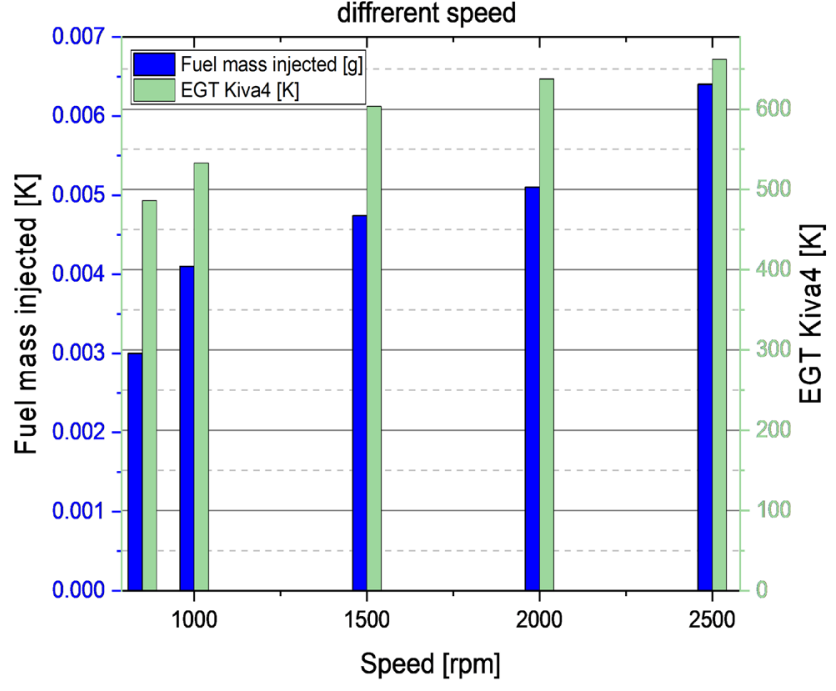

(d) $18 \mathrm{Nm}$ Load

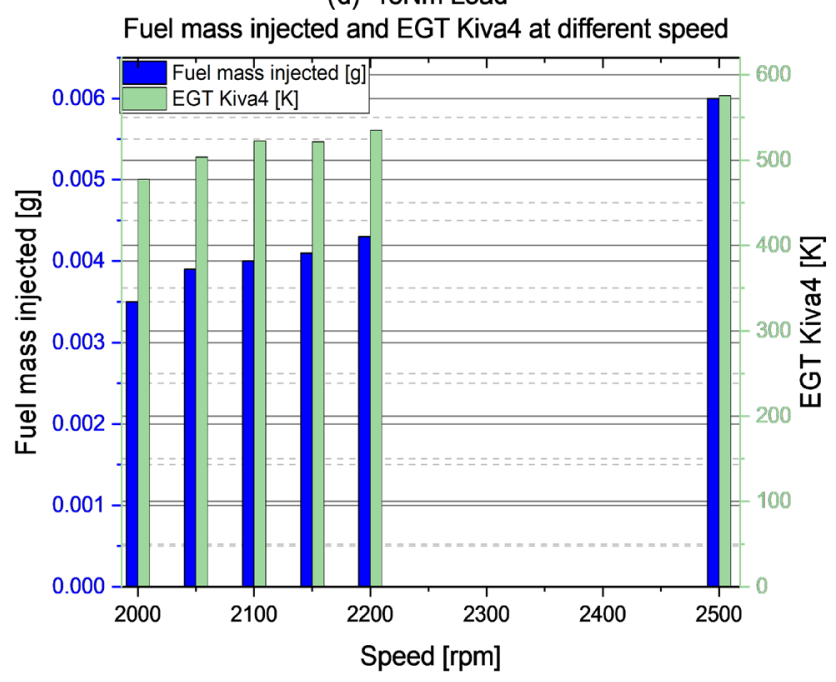

Figure 13. Injected fuel mass and the exhaust gas temperature at different engine speeds for no load and $18 \mathrm{Nm}$ load.

Kiva4 code. Experimental studies were carried out using a three cylinder, four strokes Volkswagen (VW) Polo 6 TSI 1.2 gasoline engine. For purposes of power loading, the engine was connected to an eddy-current type of dynamometer. Three distinct tests were conducted: 1) in the first test, variations in exhaust gas temperature variations were studied by keeping the engine speed constant at $2500 \mathrm{rpm}$ while varying the engine load from $2 \mathrm{Nm}$ to $23 \mathrm{Nm}$. 2) In the second test, the engine was run at no load (idling) while engine speed was varied from $850 \mathrm{rpm}$ to $2500 \mathrm{rpm}$, as exhaust gas temperature measurements were taken. 3) In the third test, the engine load was kept constant at $18 \mathrm{Nm}$ while engine speeds in the range of $2000 \mathrm{rpm}$ to $2500 \mathrm{rpm}$ were considered. To study variations in exhaust gas temperatures under test conditions, a basic grid/mesh generator, K3PREP, was employed to write an itape 17 file comprising of a $45^{\circ}$ asymmetrical mesh. This was based on the symmetry of the combustion chamber of the en- 
gine used in carrying out experimental tests. Simulations were therefore performed based on the input parameters established in the conducted tests. A considerably significant predictability of the performance characteristics of the spark ignition gasoline engine was obtained from simulations with the kiva4 code. This was evident in the appreciable agreement obtained in the simulation results when compared with the test data, under the considered test conditions. Results showed that, in the first test, power increased with load while specific fuel consumption reduced and brake thermal efficiency improved. In the second test, the exhaust gas temperatures ranged from $510 \mathrm{~K}$ to $685 \mathrm{~K}$ while simulations with the kiva4 code showed exhaust gas temperatures of $507 \mathrm{~K}$ and $667 \mathrm{~K}$ at $850 \mathrm{rpm}$ and 2500 $\mathrm{rpm}$, respectively. In the third test experimental results for the exhaust gas temperatures were $474 \mathrm{~K}$ to $575 \mathrm{~K}$ compared with kiva4 results, of $507 \mathrm{~K}$ to $667 \mathrm{~K}$ at $2000 \mathrm{rpm}$ and $2500 \mathrm{rpm}$, respectively. Between experimental and simulation results, percentage error of only between $2 \%$ to $3 \%$ was observed.

\section{Conflicts of Interest}

The authors declare no conflicts of interest regarding the publication of this paper.

\section{References}

[1] Ganesan, V. (2012) Internal Combustion Engines. Third Edition, The McGraw-Hill International Publications, London.

[2] Bietresato, M., Selmo, F. and Renzi, M. (2021) Torque Prediction Model of a CI Engine for Agricultural Purposes Based on Exhaust Gas Temperatures and CFD-FVM Methodologies Validated with Experimental Tests. Applied Sciences, 11, 3892. https://doi.org/10.3390/app11093892

[3] Kamela, W. and Warsaw (2016) Spark Ignition Engine Speed Characteristics. Lab Work, Warsaw University of Technology Faculty of Automotive and Machinery Construction Engineering Institute of Vehicle, Vol. 2, 1-4.

[4] Wojs, M.M. (2016) Load Characteristic of Combustion Engine. Lab Work, Warsaw University of Technology Faculty, Vol. 1, 1-4.

[5] Fleck, B., Gaynor, J., et al. (2006) Fast Response Exhausts Gas Temperature Measurement in IC Engines. The SAE International Journal of Passenger Cars. Electronic and Electrical Systems, 7, 598-609.

[6] Khayal, O. (2020) Sensors in Automobiles Internal Combustion Engines Sensors. Faculty of Engineering and Technology, Nile Valley University, Atbara.

[7] Lheywood, J.B. (1988) Internal Combustion Engine Fundamentals. Vol. 21. McGrawHill, Inc., New York.

[8] Ghazikhani, M., et al. (2014) Experimental Investigation of Exhaust Temperature and Delivery Ratio Effect on Emissions and Performance of a Gasoline-Ethanol Two-Stroke Engine. Case Studies in Thermal Engineering, 2, 82-90.

https://doi.org/10.1016/j.csite.2014.01.001

[9] Jaber, H., et al. (2017) Effect of Exhaust Gases Temperature on the Performance of a Hybrid Heat Recovery System. Energy Procedia, 119, 775-782. https://doi.org/10.1016/j.egypro.2017.07.110

[10] Kumar, P. (2009) Significance of the Ratio of Exhaust Temperature to Coolant Tem- 
perature and Its Effect on Various Engine Working Parameters. Proceedings of the World Congress on Engineering, Vol. 2, 1-5.

[11] McDonald, K. (2016) Los Alamos National Security, LLC Request for Information on How Industry May Partner with the Laboratory on KIVA Software. Los Alamos National Security LLC U.S. Department Energy's NNSA, No. LA-UR-16-21265, 6-9. https://doi.org/10.2172/1239897

[12] Siwale, L.Z., Kolesnikov, P.A., Bereczky, P.A. and Mbarawa, M. (2012) Effect of Oxygenated Additives in Conventional Fuels for Reciprocating Internal Combustion Engines on Performance Combustion and Emission Characteristics. Ph.D. Thesis, Tshwane University of Technology, Pretoria.

[13] Amsden, A.A. (1993) KIVA-3: A KIVA Program with Block-Structured Mesh for Complex Geometries. Los Alamos National Lab, No. LA-1 2503-MS UC-361 March 1993, 1-95.

[14] Amsden, A.A. (1997) KIVA-3V: A Block-Structured KIVA Program for Engines with Vertical or Canted Valves. LA Report, LA-13313-MS.

[15] Engine Research Center (2000, June 22) K3PREP Workshop; K3PREP \& Sample Grid. University Wisconsin-Madison, Madison, 1-43.

[16] Lawal, D.U., Imteyaz, B.A., Abdelkarim, A.M. and Khalifa, A.E. (2014) Performance of Spark Ignition Engine Using Gasoline-91 and Gasoline-95. International Journal of Innovative Science Engineering and Technology, 1, 464-469.

[17] Choudhary, S., Tiwari, A.C., Vardhan, A. and Kaushal, A. (2014) The Effect of Engine Temperature on Multi Cylinder SI Engine Performance with Gasoline as a Fuel. International Journal of Engineering Research and General Science, 2, 497-505.

[18] Pulkrabek, W.W. (2003) Engineering Fundamentals of the Internal Combustion Engine. University of Wisconsin-Platteville, Platteville, Vol. 1, 1-426.

[19] Kar, K., Roberts, S., Stone, R., Oldfield, M. and French, B. (2004) Instantaneous Exhaust Temperature Measurements Using Thermocouple Compensation Techniques. SAE International in United States, Warrendale, 1-22. https://doi.org/10.4271/2004-01-1418

[20] Morris, A.S. and Langari, R. (2021) Temperature Measurement. In: Morris, A.S. and Langari, R., Eds., Measurement and Instrumentation, Elsevier, Amsterdam, 413-468. https://doi.org/10.1016/B978-0-12-817141-7.00014-1

[21] Shelquist, R. (2015) Equations Dyno Correction Factor and Relative Horsepower. Shelquist Engineering, Colorado, USA, 1.

[22] Sodré, J.R. and Soares, S.M.C. (2003) Comparison of Engine Power Correction Factors for Varying Atmospheric Conditions. The Journal of the Brazilian Society of Mechanical Sciences and Engineering, 25, 279-285. https://doi.org/10.1590/S1678-58782003000300010

[23] Shodhganga (2013) Chapter 6. Results and Discussion. PhD Thesis, shodhganga.inflibnet.ac.in, India, 81-96.

[24] Maghbouli, A., Yang, W., An, H., Li, J., Chou, S.K. and Chua, K.J. (2013) An Advanced Combustion Model Coupled with Detailed Chemical Reaction Mechanism for D.I Diesel Engine Simulation. Applied Energy, 111, 758-770.

https://doi.org/10.1016/j.apenergy.2013.05.031

[25] Amsden, A.A., O’Rourke, P.J. and Butler, T.D. (1989) KIVA-II: A Computer Program for Chemically Reactive Flows with Sprays. Los Alamos National Laboratory, Los Alamos, LA-11560-MS. https://doi.org/10.2172/6228444

[26] Agarwal, A.K., Sinha, S. and Shukla, M. (2004) Effect of EGR on the Exhaust Gas 
Temperature and Exhaust Opacity in Compression Ignition Engines. Sadhana, 29, 275-284. https://doi.org/10.1007/BF02703777

[27] Lee, S. and Bae, C. (2002) Effects of Engine Operating Conditions on Catalytic Converter Temperature in an SI Engine. Spring Fuels \& Lubricants Meeting \& Exhibition, 1, 1-11. https://doi.org/10.4271/2002-01-1677 